\title{
Paraoxonase 1 and dietary hyperhomocysteinemia modulate the expression of mouse proteins involved in liver homeostasis
}

\author{
Joanna Suszyńska-Zajczyk ${ }^{1}$ and Hieronim Jakubowski ${ }^{1,2,3 \varpi}$ \\ IInstitute of Bioorganic Chemistry, Poznań, Poland; 2Department of Biochemistry and Biotechnology, University of Life Sciences, Poznań, Poland; \\ and ${ }^{3}$ Department of Microbiology, Biochemistry and Molecular Genetics, Rutgers-New Jersey Medical School, International Center for Public \\ Health, Newark, NJ, USA
}

Homocysteine (Hcy), a product of methionine metabolism, is elevated by the consumption of a high-methionine diet that can cause fatty liver disease. Paraoxonase 1 (Pon1), a hydrolase expressed mainly in the liver and carried in the circulation on high-density lipoprotein, participates in Hcy metabolism. Low Pon 1 activity is linked to fatty liver disease. We hypothesize that hyperhomocysteinemia and low Pon1 induce changes in gene expression that could impair liver homeostasis. To test this hypothesis, we analyzed the liver proteome of Pon $1^{-/-}$and Pon $1^{+/+}$mice fed a high methionine diet $(1 \%$ methionine in the drinking water) for 8 weeks using 2D IEF/SDS-PAGE gel electrophoresis and MALDI-TOF mass spectrometry. We identified seven liver proteins whose expression was significantly altered in Pon $1^{-/}$mice. In animals fed with a control diet, the expression of three liver proteins involved in lipoprotein metabolism (ApoE), iron metabolism ( $\mathrm{Ftl})$, and regulation of nitric oxide generation (Ddah1) was up-regulated by the Pon 1/-- genotype. In mice fed with a high-methionine diet, expression of four liver proteins was up-regulated and of three proteins was down-regulated by the Pon $1^{-/-}$genotype. The up-regulated proteins are involved in lipoprotein metabolism (ApoE), energy metabolism (Atp5h), oxidative stress response ( $\operatorname{Prd} \times 2)$, and nitric oxide regulation (Ddah1). The down-regulated proteins are involved in energy metabolism (Gamt), iron metabolism (Ftl), and catechol metabolism (Comt). Expression of one protein (Ftl) was up-regulated both by the Pon $1^{-/}$genotype and a high-methionine diet. Our findings suggest that Pon1 interacts with diverse cellular processes - from lipoprotein metabolism, nitric oxide regulation, and energy metabolism to iron transport and antioxidant defenses - that are essential for normal liver homeostasis and modulation of these interactions by a high-methionine diet may contribute to fatty liver disease.

Key words: Pon1, high-methionine diet, hyperhomocysteinemia, mouse liver proteome

Received: 17 July, 2014; revised: 29 September, 2014; accepted: 07 October, 2014; available on-line: 28 October, 2014

\section{INTRODUCTION}

Elevated homocysteine (Hcy) levels have long been known to be linked to liver disease. Indeed, fatty liver is a common finding in nutritionally induced hyperhomocysteinemia (HHcy) due to methionine (Met) overload, folate deficiency, or excessive alcohol intake (Werstuck et al., 2001; Hirsch et al., 2005; Kaplowitz et al., 2007). Although there is evidence suggesting that Hcy-induced endoplasmic reticulum and oxidative stress mediates liver damage by promoting apoptotic cell death, inflammation, insulin resistance, and deregulated lipid metabolism (Kaplowitz et al., 2007), the exact mechanism underlying Hcy-induced liver damage is unclear.

Paraoxonase 1 (PON1), named for its ability to hydrolyze the organophosphate paraoxon (Costa et al., 2013), is expressed in the liver, kidney, brain, and colon (Mackness et al., 2010), circulates in the blood attached to high-density lipoproteins (HDL), and is localized to all organs (Marsillach et al., 2008). Clinical studies have linked PON1 activity to cardiovascular disease (Domagala et al., 2006; Bayrak et al., 2012) and it has been found that Pon1 protects against high-fat diet-induced atherosclerosis in mice (Shih et al., 1998) and humans (Bhattacharyya et al., 2008).

Several studies have also linked PON1 to liver disease. For example, serum PON1 activity decreases in patients with chronic hepatitis or cirrhosis and the magnitude of the decrease correlates to the extent of liver damage (Ferre et al., 2002; Marsillach et al., 2007). Serum PON1 activity is also lower in cows suffering from fatty liver compared with healthy animals (Farid et al., 2013). In experimental rat cirrhosis model, the decrease in Pon1 activity is also correlated with the extent of liver damage (Ferre et al., 2001). Furthermore, in mouse models, deletion of the Pon 1 gene increases the frequency of fatty liver in animals fed with a high-fat diet (Garcia-Heredia et al., 2013) while overexpression of Pon1 protects against the development of liver disease induced by $\mathrm{CCl}_{4}$ (Zhang et al., 2008). Because Pon 1 -knockout animals exhibit elevated levels of oxidative stress markers, the hepatoprotective function of Pon1 has been suggested to be due to its ability to act as an antioxidant (Garcia-Heredia et al., 2013). However, the mechanism underlying the anti-oxidative function of Pon1 is not clear (Perla-Kajan \& Jakubowski, 2010; 2012).

Pon1 occupies a juncture between the metabolisms of HDL/PON1 and Hcy (Jakubowski, 2008b) that may ac-

e-mail: jakubows@njms.rutgers.edu

Abbreviations: Hcy, homocysteine; Met, methionine; Pon1, paraoxonase 1; Cbs, cystathionine $\beta$-synthase; ApoA-I, apolipoprotein A-I; ApoE, apolipoprotein E; Atp5h, ATPase subunit d; Comt, catechol-O-methyltransferase; Ddah1, dimethylarginine dimethylaminohydrolase 1; Ftl1, ferritin light subunit; Gamt, guanidinoacetate$\mathrm{N}$-methyltransferase; IEF/SDS-PAGE, isoelectric focusing/sodium dodecylsulphate polyacrylamide gel electrophoresis; MALDI-TOF, matrix assisted laser desorption ionization-time of flight; Prdx2, peroxiredoxin 2 
count for their role in liver disease. For example, in humans Hcy is a negative determinant of HDL and PON1 activity (Lacinski et al., 2004; Wehr et al., 2009) and attenuates Apoa1 and Pon 1 gene expression both in mice and humans (Robert et al., 2003; Liao et al., 2006; Jiang et al., 2012). We found that HDL and purified PON1 protein have the ability to hydrolyze Hcy-thiolactone (Jakubowski 2000), thereby protecting against protein N-homocysteinylation in humans (Perla-Kajan \& Jakubowski, 2010) and mice (Borowczyk et al., 2012a). N-Homocysteinylation causes protein damage (Jakubowski, 1999; Glowacki \& Jakubowski, 2004) and is linked to atherosclerosis (Perla-Kajan et al., 2008), stroke (Undas et al., 2004), and coronary artery disease (Undas et al., 2005). N-Hcy-proteins, including N-Hcy-HDL (Jakubowski, 2002) and N-Hcy-ApoA-I (Ishimine et al., 2010), are present at basal levels in normal human plasma and increase in hyperhomocysteinemic individuals (Jakubowski et al., 2008). $N$-Hcy-proteins are also elevated in the liver and plasma of hyperhomocysteinemic $\mathrm{Cbs}^{-1-}$ mice (Jakubowski et al., 2009). In vitro, N-homocysteinylation of HDL and Pon1 causes a loss of their atheroprotective function (Ferretti et al., 2003). We have also found that the Pon1-null mice show impaired metabolic conversion of Hcy-thiolactone to Hcy, elevated brain Hcy-thiolactone levels, and increased susceptibility to the neurotoxic effects of Hcy-thiolactone (Borowczyk et al., 2012a). Taken together, these findings indicate that Pon1 plays an important role in Hcy metabolism.

We hypothesize that interactions between Pon1 deficiency and HHcy impair liver homeostasis. To gain insight into the role of Pon1 in the liver and to identify metabolic pathways regulated by Pon1 and HHcy, we examined liver proteomes of Pon $1^{-/-}$and Pon $1^{+/+}$mice fed with a control diet or a high-Met diet $(1 \%$ Met in drinking water) for 8 weeks using 2D IEF/SDS-PAGE gel electrophoresis and MALDI-TOF mass spectrometry.

\section{MATERIALS AND METHODS}

Mice and diets. Colonies of Pon $1^{-1-}$ mice on the C57BL/6J genetic background (Shih et al., 1998) and wild type Pon $1^{+/+}$littermates were bred and housed at the New Jersey Medical School Animal Facility. Female mice ( $\mathrm{n}=8$ per group) were maintained on a standard rodent chow diet (LabDiet 5010, Purina Mills International, St. Louis, MO; contains $0.66 \%$ methionine). At 4 weeks of age, half of Pon $1^{-/-}$and Pon $1^{+/+}$mice were provided with $1 \%$ methionine in drinking water (high-Met diet) for 8 weeks (Velez-Carrasco et al., 2008, Borowczyk et al., 2012b). Four experimental groups of animals were studied: 1) Pon ${ }^{-/-}$mice, control diet; 2) Pon $1^{+/+}$mice, control diet; 3) Pon $1^{-/-}$mice, high-Met diet; 4) Pon $1^{+/+}$ mice, high-Met diet. Supplementation of drinking water with $1 \%$ Met did not affect water intake by the mice. Consumption of $1 \%$ Met in drinking water did not affect body weight of the mice. Animal procedures were approved by the Institutional Animal Care and Use Committee at the Rutgers-New Jersey Medical School.

Genotyping. To establish the status of the Pon1 locus, genomic DNA was isolated and genotyped by PCR using the Pon1 forward primer p1 (5'-TGGGCTGCAGGTCTCAGGACTGA-3'), Pon 1 exon 1 reverse primer p2 (5'-ATAGGAAGACCGATGGTTCT-3'), and neomycin cassette reverse primer p3 (5'-TCCTCGTGCTTTACGGTATCG-3') (Shih et al., 1998). Briefly, the 10 $\mu \mathrm{L}$ PCR mixture contained $100 \mathrm{ng}$ purified mouse DNA, $5 \mu l$ PCR MasterMix (Fermentas), 0.5 $\mu \mathrm{L}$ primer p1, p2, p3, 0.5 units of Taq polymerase (Fermentas) and water to $10 \mu \mathrm{L}$. The thermal cycling reaction was run for 34 cycles of $92^{\circ} \mathrm{C}$ for $30 \mathrm{~s}, 65^{\circ} \mathrm{C}$ for $40 \mathrm{~s}$ and $72^{\circ} \mathrm{C}$ for 90 s. The 144 bp amplicon from the Pon $1^{+/+}$wild-type allele (obtained with p1, p2 primers) and the $240 \mathrm{bp}$ amplicon from the Pon $1^{-1-}$ knockout allele (obtained with p1, p3 primers) were distinguished on a 1.5\% agarose gel stained with SYBRSafe (Invitrogen) (Suszynska-Zajczyk et al., 2014). Pon1 genotype was confirmed by enzymatic assays of serum paraoxonase (POase) and arylesterase (PhAcase) activities (Perla-Kajan \& Jakubowski, 2010).

Enzymatic assys. POase and PhAcase activity assays were carried out at $25^{\circ} \mathrm{C}$ as previously described (PerlaKajan \& Jakubowski, 2010). Reactions were initiated by adding $5 \mu \mathrm{L}$ serum to $500 \mu \mathrm{L}$ mixtures containing 50 $\mathrm{mM} \mathrm{K-HEPES} \mathrm{buffer} \mathrm{(pH} \mathrm{7.4),} 1 \mathrm{mM} \mathrm{CaCl}_{2}$, and $2 \mathrm{mM}$ paraoxon or $5 \mathrm{mM}$ phenyl acetate. For POase activity assays, the generation of $p$-nitrophenol from paraoxon was monitored at $412 \mathrm{~nm}$ for 2-min time periods, and reaction rates $\left(\mathrm{A}_{412} / \mathrm{min}\right)$ were calculated. For PhAcase activity assays, the generation of phenol from $5 \mathrm{mM}$ phenyl acetate (PhAc) was monitored at $270 \mathrm{~nm}$ for 2 $\mathrm{min}$, and rates (A270/min) were calculated from the first $0.5 \mathrm{~min}$ of the reaction. Controls in which Pon1 was inactivated with $1 \mathrm{mM}$ EDTA were subtracted from the results $\left(0.10-0.14 \mathrm{~A}_{270} / \mathrm{min}\right.$ and $0.0001 \mathrm{~A}_{412} / \mathrm{min}$ for reactions with $\mathrm{PhAc}$ and paraoxon, respectively).

Hcy assays. Total Hcy and N-Hcy-protein were assayed by HPLC-based methods with post-column derivatization and fluorescence detection as previously described (Jakubowski 2008a; Jakubowski et al., 2008; Jakubowski et al., 2009).

Protein extraction. Liver proteins were extracted using the phenol method (Faurobert et al., 2007) as previously described (Suszynska-Zajczyk et al., 2014a). Briefly, liver tissue was disintegrated by grinding with dry ice using a mortar and pestle. A $100 \mathrm{mg}$ portion of the pulverized liver material was extracted with $0.9 \mathrm{~mL}$ of extraction buffer (0.5 M Tris/ $\mathrm{HCl} \mathrm{pH} 7.5,50 \mathrm{mM}$ EDTA, $0.1 \mathrm{M} \mathrm{KCl}, 0.7 \mathrm{M}$ sucrose, 2\% w/v DTT) containing protease inhibitors (Protease Inhibitor Mix, GE Healthcare) and $1 \mathrm{~mL}$ phenol containing $0.1 \%$ hydroxyquinoline with vigorous shaking $\left(10 \mathrm{~min}, 4^{\circ} \mathrm{C}\right)$. The mixture was centrifuged $\left(12000 \times g, 10 \mathrm{~min}, 4^{\circ} \mathrm{C}\right)$, the phenol layer collected, and extracted again with an equal volume of the extraction buffer. The phenol layer was separated by centrifugation, collected, and the proteins precipitated with 5 volumes of $0.1 \mathrm{M}$ ammonium acetate in methanol $\left(-80^{\circ} \mathrm{C}, 2\right.$ days). The protein pellet was collected by centrifugation $\left(12000 \times \mathrm{g}, 10 \mathrm{~min}, 4^{\circ} \mathrm{C}\right)$, washed 3 times with $0.1 \mathrm{M}$ ammonium acetate in methanol, followed by 5-min washes with $80 \%$ and $100 \%$ acetone, and allowed to air dry.

Liver protein samples were dissolved in IEF rehydration buffer ( $7 \mathrm{M}$ urea, $2 \mathrm{M}$ thiourea, 2\% CHAPS). Insoluble material was removed by centrifugation (16000 $\times g$, $20 \mathrm{~min}$ ). Protein concentration was determined using a commercial 2-D Quant kit (GE Healthcare).

Two-dimensional IEF/SDS-PAGE. Liver protein separations and image analysis were carried out as previously described (Luczak et al., 2011; Suszynska-Zajczyk et al., 2014a). IPG strips (11 cm, pH 4-7, GE Healthcare) were rehydrated overnight in IEF buffer containing liver protein samples $(0.3 \mathrm{mg} / \mathrm{strip}), 55 \mathrm{mM} \mathrm{DTT}^{\prime} \mathrm{T}, 0.5 \%$ (v/v) ampholite $\mathrm{pH}$ 4-10 (GE Healthcare). The strips were subjected to IEF on IPGphor III apparatus (GE Healthcare) using a ramping voltage (50-6000 V) to final 25000 Vh. After IEF, IPG strips were incubated for $15 \mathrm{~min}$ in an equilibration buffer (6 M urea, 2\% w/v SDS, $30 \% \mathrm{v} / \mathrm{v}$ 
glycerol, $50 \mathrm{mM}$ Tris/ $\mathrm{HCl}, \mathrm{pH} 8.8$ ) containing $1 \% \mathrm{w} / \mathrm{v}$ DT'T during the first equilibration step and $2.5 \%$ iodoacetamide $\mathrm{w} / \mathrm{v}$ during the second equilibration step. The second dimension was carried out using $11 \%$ polyacrylamide gels $(24 \times 24 \mathrm{~cm})$ on an Ettan DALT six system (GE Healthcare) according to the manufacturer's instructions. For each sample, a 2D analysis was repeated three times. After electrophoresis, gels were stained with Blue Silver overnight (Candiano et al., 2004) and scanned using an Umax scanner and LabScan software (GE Healthcare).

The images were analyzed using the Image Master Platinum software version 7.0 (GE Healthcare). Spots were detected automatically without filtering. Gel patterns were automatically matched between groups. In addition, all individual matched spots were validated manually to ensure the correctness of spot matching. For each identified protein, the relative abundance (\% Volume) was calculated from its area and intensity divided by the total volume of all protein spots on a gel. This procedure corrects for small variations between individual gels due to protein loading and staining (Luczak et al., 2011).

Mass spectrometry. Mass spectrometry analyses have been carried out as previously described (Luczak et al., 2011; Suszynska-Zajczyk et al., 2014b). Briefly, protein spots were manually excised from gels using Pasteur pipets, transferred to Eppendorf tubes, de-stained by series of washes with $50 \mathrm{mM}$ ammonium bicarbonate, $25 \mathrm{mM}$ ammonium bicarbonate $/ 50 \%$ acetonitrile, and dehydrated with neat acetonitrile according to a procedure described in (Shevchenko \& Shevchenko, 2001). The dried gel pieces were digested with $10 \mu \mathrm{L} 20 \mathrm{ng} / \mu \mathrm{L}$ trypsin (Promega), $25 \mathrm{mM}$ ammonium bicarbonate $\left(37^{\circ} \mathrm{C}, 16\right.$ h). Tryptic peptides were recovered from gel pieces by adding acetonitrile (to $10 \%$ ), sonication in an ultrasound bath for $5 \mathrm{~min}$, followed by $0.5 \mathrm{~h}$ incubation at $4^{\circ} \mathrm{C}$.

The proteins were identified using UltrafleXtreme MALDI-TOF/TOF (Bruker Daltonics, Germany) mass spectrometer operating in reflector mode. Positively charged ions in the $\mathrm{m} / \mathrm{z}$ range 850-3500 were analyzed. $0.5 \mu \mathrm{L}$ of the sample was co-crystallized with a CHCA matrix and spotted directly on MALDI AnchorChip 800 $\mathrm{nm}$ target (Bruker Daltonics). For data validation, external calibration was performed with a standard mixture of peptides with masses ranging from 700 to $3500 \mathrm{Da}$ (Peptide Calibration Standards 1 - Bruker). Standards were spotted on calibration spots and calibration was performed after each four samples (samples surrounding calibration spot). Flex control v 3.3 was used for the acquisition of spectra and all further data processing was carried out using Flex analysis v 3.3. Monoisotopic peptide masses were assigned and used for databases search. Additionally five most intensive peaks for each sample were chosen to be fragmented in LIFT mode. MS and MS/MS spectra acquired for each sample were combined and used for Mascot MS/MS Ion Search. For data processing and Mascot (Matrix Science, London, UK) analysis Bruker Bio'Tools 3.2 package was employed. The proteins were identified against UniProtKB/Swiss-Prot protein database. The protein search was done using the following search parameters: MS mass tolerance $\pm 0.2 \mathrm{Da}, \mathrm{MS} / \mathrm{MS}$ mass tolerance $0.5 \mathrm{Da}$, one allowed missed cleavage, cysteine treated with iodoacetamide to form carbamidomethyl-cysteine and methionine in the oxidized form.

Data treatment and statistical analysis. For each animal in the four experimental groups (4 animals/ group), the analyses were repeated 2-3 times. The relative abundance of each protein spot (\% Volume) was calculated as its volume divided by the total volume of all spots (Luczak et al., 2011). Data are expressed as mean \pm S.D. Data for each protein spot had a normal distribution. The differences between the groups were analyzed by ANOVA. Unpaired Student's $t$-test was used to test differences between two groups. Statistical analyses were carried out using Statistica 8.0 software.

\section{RESULTS}

\section{Dietary hyperhomocysteinemia in Pon $1^{-/-}$and Pon $1^{+/+}$ mice}

To identify genes regulated by Pon 1 genotype and to examine the interaction between the Pon 1 genotype and $\mathrm{HHcy}$, we analyzed liver proteomes of Pon $1^{-1-}$ mice and their Pon $1^{+/+}$littermates in the absence and presence of HHcy. We used a mouse model of dietary HHcy in which feeding a high-Met diet elevates plasma Hcy (Zhou et al., 2001), and leads to hepatic steatosis after prolonged (16-20-week) exposure (Werstuck et al., 2001). The extent of HHcy was assessed by measurements of plasma tHcy and N-Hcy-protein levels. Plasma tHcy levels in Pon $1^{-/-}$and Pon $1^{+/+}$mice fed a standard chow diet were $8.5 \pm 1.9 \mu \mathrm{M}$ and $7.4 \pm 2.2 \mu \mathrm{M}$, and increased to $48 \pm 16 \mu \mathrm{M}$ and $77 \pm 45 \mu \mathrm{M}$, respectively, in animals fed with a high-Met diet for 8 weeks. These levels of HHcy are known to induce the accumulation of cholesterol and triglycerides in mouse livers with no apparent fibrosis or necrosis after 16-20 weeks (Werstuck et al., 2001). Plasma N-Hcy-protein levels increased from basal levels of $1.4 \pm 0.5 \mu \mathrm{M}\left(\right.$ Pon $\left.^{-/-}\right)$and $1.2 \pm 0.4 \mu \mathrm{M}\left(\right.$ Pon $\left.^{+/+}\right)$to $3.8 \pm 1.8 \mu \mathrm{M}$ and $5.4 \pm 2.9 \mu \mathrm{M}$ in hyperhomocysteinemic Pon $1^{-/-}$and Pon $1^{+/+}$mice, respectively.

\section{Identification of differentially expressed proteins in Pon $1^{-/}$mouse liver}

Mouse liver protein separation by IEF/SDS-PAGE yielded several hundred distinct protein spots (Fig. 1),

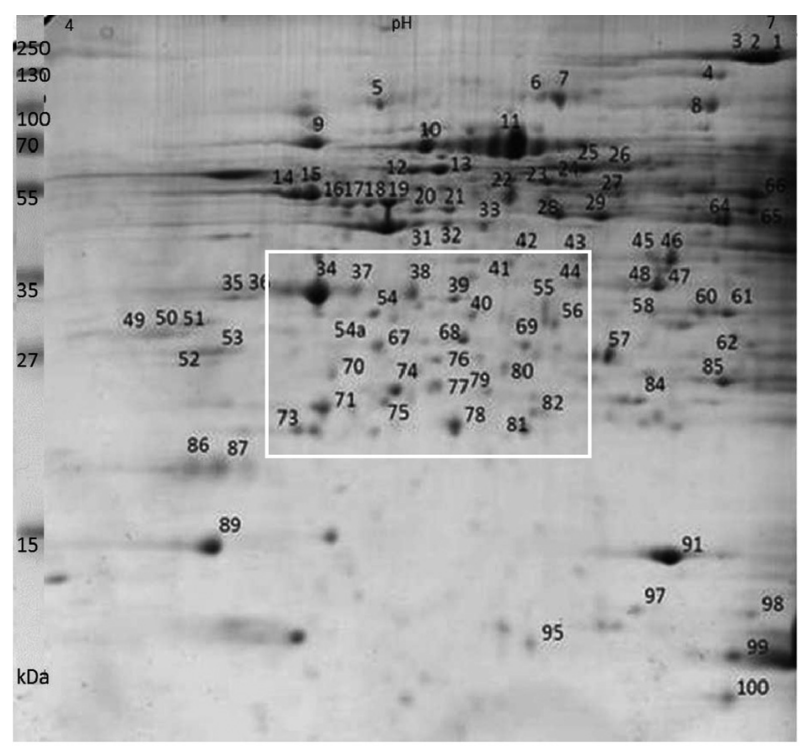

Figure 1. Representative IEF/SDS-PAGE gel showing the liver proteome of a wild type C57BL/6J mouse.

Left to right: IEF $\mathrm{pH}$ gradient from $\mathrm{pH} 4$ to $\mathrm{pH}$ 7. Top to bottom: SDS-PAGE; molecular weight markers, 10 to $100 \mathrm{kDa}$, shown on the left. Numbers indicate spots of proteins whose identity has been established by mass spectrometry. White rectangle outlines an area containing proteins whose expression was affected by the Pon 1 genotype and/or high-Met diet. Identities of the differentially expressed proteins are described in Table 1. Identities of other proteins are described in ref. (Suszynska-Zajczyk et al., 2014a). 
Table 1. Characteristics of C57BL/6J mouse liver proteins regulated by Pon 1/- genotype identified by proteomic analyses ${ }^{1}$

\begin{tabular}{|c|c|c|c|c|c|c|c|c|c|}
\hline $\begin{array}{l}\text { Spot } \\
\text { No. }\end{array}$ & Protein name & $\begin{array}{l}\text { Theore } \\
\text { Mass } \\
(\mathrm{kDa})\end{array}$ & cal & $\begin{array}{l}\text { Sequence } \\
\text { coverage } \\
(\%)\end{array}$ & $\begin{array}{l}\text { Matched } \\
\text { peptides } \\
(\mathrm{n})\end{array}$ & $\begin{array}{l}\text { Gene } \\
\text { name }\end{array}$ & Accession No. & Score & $\%$ Volume \\
\hline 39 & Apolipoprotein E & 35.9 & 5.46 & 35 & 13 & Apoe & P08226 & 119 & 0.30 \\
\hline 41 & $\begin{array}{l}\text { Dimethylarginine dimethyla- } \\
\text { minohydrolase } 1\end{array}$ & 31.6 & 5.63 & 39 & 10 & Ddah1 & Q9CWS0 & 103 & 0.15 \\
\hline 73 & Peroxiredoxin-2 & 21.9 & 5.20 & 35 & 5 & $\operatorname{Prdx2}$ & Q61171 & 93 & 0.37 \\
\hline 75 & Catechol-O-metyltransferase & 29.7 & 5.52 & 37 & 8 & Comt & O88587 & 89 & 0.21 \\
\hline 76 & $\begin{array}{l}\text { Guanidinoacetate } N \text {-methyl- } \\
\text { transferase }\end{array}$ & 26.6 & 5.43 & 31 & 5 & Gamt & O35969 & 69 & 0.20 \\
\hline 77 & Apolipoprotein A-I & 30.4 & 5.52 & 30 & 8 & Apoa1 & Q00623 & 81 & 0.56 \\
\hline 78 & $\begin{array}{l}\text { ATP synthase subunit d, } \\
\text { mitochondrial }\end{array}$ & 18.7 & 5.52 & 50 & 9 & Atp5h & Q9DCX2 & 142 & 0.71 \\
\hline 81 & Ferritin light chain 1 & 20.8 & 5.66 & 49 & 8 & Ftl1 & P29391 & 128 & 0.34 \\
\hline
\end{tabular}

1Spot numbers are identical to those shown in Fig. 1. Values of the \% Volume are averages of 6 measurements for indicated protein in wild type Pon $1^{+/+}$mice.

100 of which have been identified by MALDI-TOF mass spectroscopy (Suszynska-Zajczyk et al., 2014). Eight of these proteins were found to have significantly changed expression in response to Pon 1-/- genotype and/or a high-Met diet. The expression levels of the other identified proteins were not altered by the Pon 1 genotype or high-Met diet. Characteristics of the differentially expressed proteins are shown in Table 1. Closeup views of representative IEF/SDS-PAGE separations of differentially expressed proteins are shown in Fig. 2. Quantification of the levels (\% Volume) for each of the differentially expressed protein is shown in Fig. 3.

\section{Liver proteins regulated by Pon 1 genotype}

In mice fed with a standard chow diet the differential expression (Pon $1^{-/-}$vs. Pon $1^{+/+}$mice) of three liver proteins was higher $(1.20$ to 1.27 -fold, $P<0.01)$ (Table 2). The proteins up-regulated by the Pon $1^{-/-}$genotype are involved in lipoprotein metabolism (apolipoprotein E,
A.

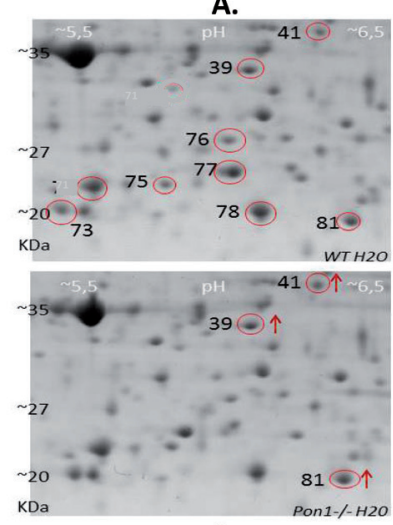

C.

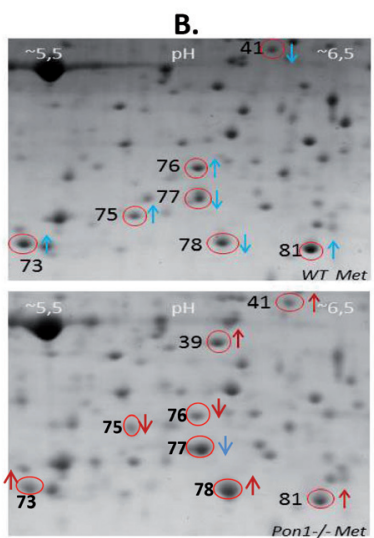

D.
Figure 2. Close-up views of representative IEF/SDS-PAGE gels showing mouse liver proteins whose expression was affected by Pon 1 genotype and/or high-Met diet.

Analyses were carried out for the following groups of mice: panel A - Pon $1^{+/+}$, control diet; panel B - Pon $1^{+/+}$, high-Met diet; panel C - Pon 1-1-, control diet; panel D - Pon 1-1, high-Met diet. Up and down arrows indicate the direction of the change dependent of Pon1 genotype (panels C and D) and high-Met diet (panel B).
ApoE), regulation of nitric oxide generation (dimethylarginine dimethylaminohydrolase 1, Ddah1), and iron metabolism (ferritin light chain, Ftl) (Table 2).

\section{Liver proteins regulated by high-Met diet}

In wild type Pon $1^{+/+}$mice, 1\%-Met diet significantly down-regulated three liver proteins (apolipoprotein A-I - ApoA-I, Atp5h, and Ddah1; -1.14 to -1.47 -fold, $P<0.001$ ) and up-regulated four proteins (Gamt, Ftl, Prdx2, catechol-O-methyltransferase - Comt (1.22 to 1.68-fold, $P<0.01$; Table 2). With the exception of Ftl and Ddah1, the expression of these proteins was not significantly altered by the Pon $1^{-/}$genotype in mice fed a control diet (Table 2).

\section{Liver proteins regulated by Pon 1 genotype and high- Met diet}

The expression of four proteins: Gamt, Atp5h, Prdx2, and Comt, became dependent on the Pon 1-/- genotype only in mice fed with high-Met diet and was decreased -1.45 to -2.04 -fold, $P<0.001$ (Gamt, Comt) or increased 1.15 to 1.32 -fold, $P<0.01$ (Atp5h, Prdx2) in Pon $1^{-1-}$ animals (Table 2). The expression of one protein, ApoE, was dependent on the Pon $1^{-1-}$ genotype regardless of the presence or absence of the dietary HHcy (Table 2). For one protein, Ftl, direction of the regulation by the Pon1-/- genotype was dependent on the diet: the up-regulation of Ftl by the Pon 1-/- genotype, observed in mice fed with the standard chow diet, was changed to downregulation in animals fed with high-Met diet (Table 2).

Western blot analysis was performed for ApoA-I and Ftl to validate the IEF/SDS-PAGE results. As shown in Fig. 4, ApoAI was lowered by high-Met diet both in Pon $1^{-/-}$and Pon $1^{+/+}$mice (Fig. 4A), similar to the results obtained by the IEF/SDS-PAGE analysis (Fig. 4D). Western blot analysis also showed that Ftl was elevated by high-Met diet in Pon $1^{+/+}$mice, but not in Pon 1-/- animals (Fig. 4B), consistent with the results of the IEF/ SDS-PAGE analyses (Fig. 4E).

\section{High-Met diet reduces serum Pon1 levels}

Hepatic Pon1 expression and activity (Robert et al., 2003) as well as serum Pon1 activity (Jiang et al., 2012) 

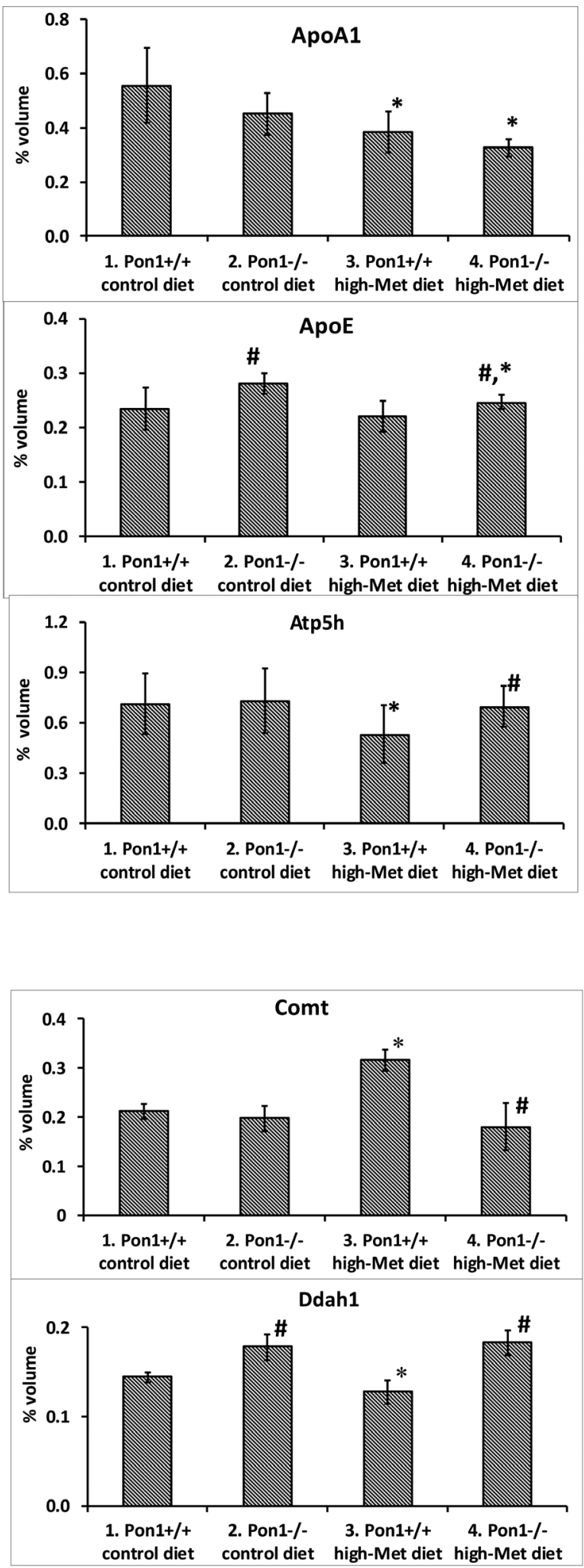

were reported to be significantly reduced in severely hyperhomocysteinemic $\mathrm{Cbs}^{-1-}$ mice. Hepatic Pon1 activity is also reduced in $\mathrm{Cbs}^{+/-}$mice fed with $0.5 \%$ Met in drinking water for 8 weeks; these mice have mild HHcy with plasma tHcy $=15 \mu \mathrm{M}$ (Robert et al., 2003). Thus, it is likely that dietary hyperhomocysteinemia with plasma tHcy $=77 \mu \mathrm{M}$ in our wild type Pon $1^{+/+}$mice would
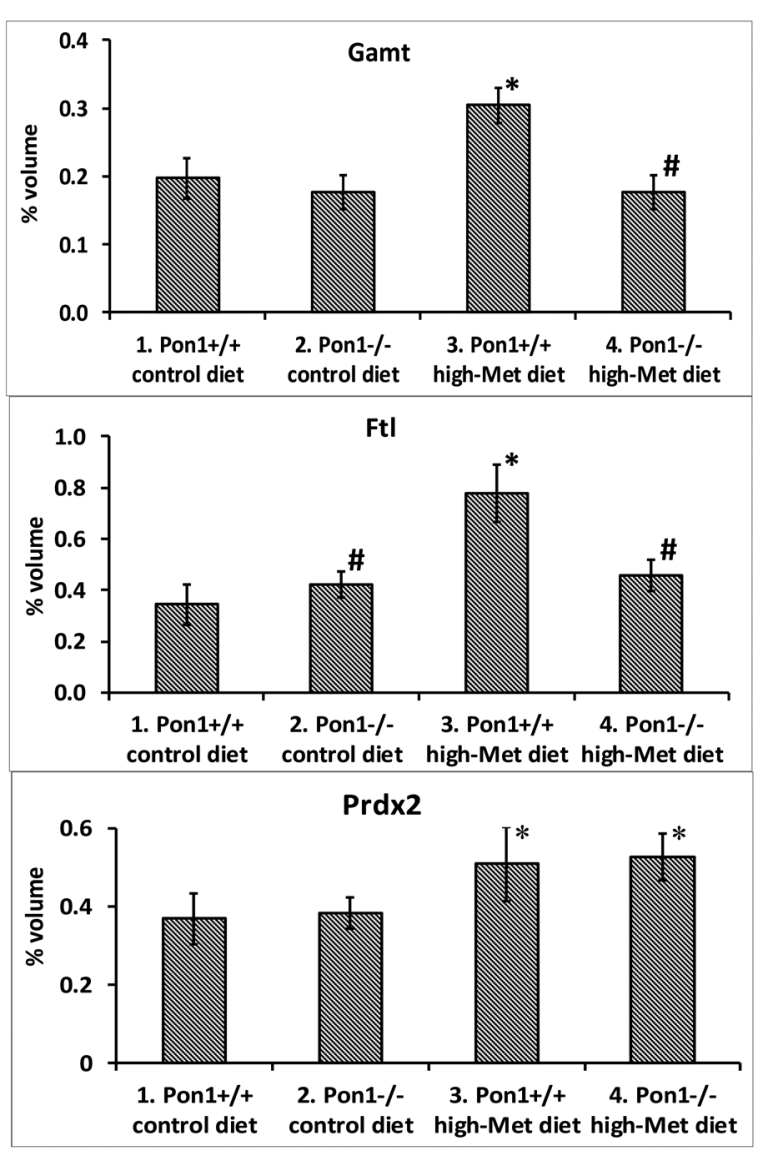

Figure 3. Mouse liver protein expression levels as a function of Pon 1 genotype and/or high-Met diet.

Each panel shows expression level (\% volume) for the indicated liver protein determined for the following groups of mice: 1 Pon $1^{+/+}$, control diet; 2 - Pon $1^{-/}$, control diet; 3 - Pon $1^{+++}$, high-Met diet; $4-$ Pon $1^{-1-}$, high-Met diet. Symbols ${ }^{*}$ and ${ }^{*}$ indicate significant $(P<0.05)$ effects of the Pon $1^{-/}$genotype and high-Met diet, respectively.

also lead to reduced Pon1 expression. To examine this possibility, we measured Pon1 activity in serum from wild type Pon $1^{+/+}$mice fed with a hyperhomocysteinemic high-Met diet. We found that POase and PhAcase activities were significantly reduced in wild type mice that were fed with a high-Met-diet (by $18-22 \%$ in females and $40 \%$ in males; Table 3). Consistent with previous work (Shih et al., 1998), Pon1-/- mice did not exhibit any Pon1 activity (Table 3). The reduction of Pon1 activity by HHcy may contribute to altered protein expression induced by a high-Met diet.

\section{DISCUSSION}

In the present work we used Pon1-/- mice in a proteomic study to discover metabolic pathways regulated by the Pon 1 genotype and high-Met diet in the liver. We found that: 1) liver proteins involved in lipid homeostasis (ApoE), energy metabolism (Atp5h, Gamt), iron transport $(\mathrm{Ftl})$, oxidative stress response $(\operatorname{Prdx} 2)$, catechol metabolism (Comt), and nitric oxide regulation (Ddah1) were regulated by the Pon1-/- genotype; 2) highMet diet interacts with the Pon $1^{-/-}$genotype to modify its effects on protein expression; 3) proteins involved in 
Table 2. Differentially expressed liver proteins regulated by Pon 1/-- genotype and/or high-Met diet.

\begin{tabular}{|c|c|c|c|c|c|}
\hline \multirow[t]{2}{*}{ Protein description (Spot \#) ${ }^{1}$} & \multirow[t]{2}{*}{$\begin{array}{l}\text { Gene } \\
\text { name }\end{array}$} & \multicolumn{2}{|c|}{$\begin{array}{l}\text { Fold change } \\
\text { Pon } 1^{-/-} \text {vs. Pon } 1^{+/+}\end{array}$} & \multicolumn{2}{|c|}{$\begin{array}{l}\text { Fold change } \\
1 \% \text { Met vs. std diet }\end{array}$} \\
\hline & & Control diet & 1\%-Met diet & Pon $1^{+/+}$ & Pon1-1- \\
\hline $\begin{array}{l}\text { Lipoprotein metabolism } \\
\text { Apolipoprotein A1 (\#77) }\end{array}$ & Apoa1 & -1.11 & -1.05 & $-1.47^{a}$ & $-1.39 a$ \\
\hline Apolipoprotein E (\#39) & ApoE & $1.20^{\mathrm{b}}$ & $1.11^{c}$ & -1.06 & $-1.14^{a}$ \\
\hline $\begin{array}{l}\text { Energy metabolism } \\
\text { ATP synthase subunit d (\#78) }\end{array}$ & Atp5h & 1.03 & $1.32^{\mathrm{b}}$ & $-1.35^{b}$ & -1.05 \\
\hline Guanidinoacetate $N$-methyltransferase (\#76) & Gamt & 1.05 & $-2.04^{a}$ & $1.62^{\mathrm{a}}$ & $-1.32^{b}$ \\
\hline $\begin{array}{l}\text { Iron metabolism and homeostasis } \\
\text { Ferritin light chain (\#81) }\end{array}$ & Ftl & $1.27^{b}$ & $-1.70 c$ & $2.29 a$ & 1.09 \\
\hline $\begin{array}{l}\text { Oxidative stress response } \\
\text { Peroxiredoxin } 2(\# 73)\end{array}$ & Prdx2 & 1.07 & $1.15^{b}$ & $1.28^{\mathrm{a}}$ & $1.37^{a}$ \\
\hline $\begin{array}{l}\text { Catechol metabolism } \\
\text { Catechol-O-methyl transferase (\#75) }\end{array}$ & Comt & 1.03 & $-1.45^{a}$ & $1.36^{\mathrm{a}}$ & -1.06 \\
\hline $\begin{array}{l}\text { Nitric oxide generation } \\
\text { Dimethylarginine } \\
\text { dimethylaminohydrolase } 1(\# 41)\end{array}$ & Ddah1 & $1.23^{a}$ & $1.44^{a}$ & $-1.14^{a}$ & 1.03 \\
\hline
\end{tabular}
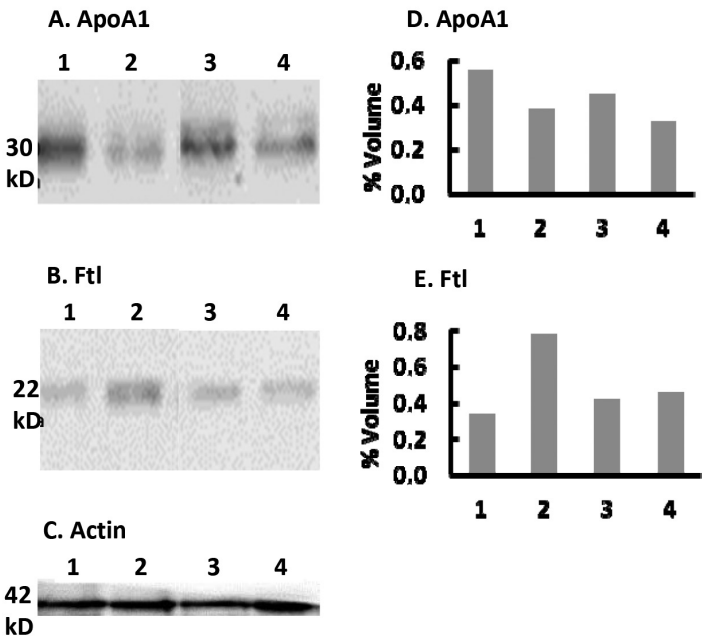

Figure 4. Western blot validation of IEF/SDS-PAGE results.

Panels $A$ and $B$ show Western blots for ApoA-I and Ftl, respectively. Panel $C$ shows Western blot for actin that indicates equal loading in the four lanes. Panels D and E show '\% Volume' for ApoA-I and $\mathrm{Ftl}$, respectively from IEF/SDS-PAGE analyses of the same samples. The following groups of mice were studied: lane 1 - Pon $1^{+/+}$, control diet; lane 2 - Pon $1^{+/+}$, high-Met diet; lane 3 - Pon 1-/, control diet; lane 4 - Pon 1-1, high-Met diet.

energy metabolism (Atp5h, Gamt), oxidative stress response (Prdx2), and catechol metabolism (Comt) show the Pon $1^{-/-}$genotype-dependent expression only in mice fed with a high-Met diet. Alterations in the liver proteome, observed in the present work after 8 week exposure to HHcy, may precede the development of fatty liver disease that is observed after 16-20 week-long exposure (Werstuck et al., 2001).

The function of Pon1 in the liver has not been fully explored. In the present work we identified three liver proteins: ApoE, Ftl, and Ddah1, whose expression was increased in Pon $1^{-/}$mice fed with a control diet, compared with Pon $1^{+/+}$animals (Table 2). This finding suggests that in the absence of HHcy Pon1 interacts with proteins involved in lipid metabolism (ApoE), iron metabolism (Ftl), and nitric oxide generation (Ddah1).
In Pon1-/- mice fed with a hyperhomocysteinemic high-Met diet, three liver proteins with decreased expression (Gamt, Ftl, and Comt) and four with increased expression (ApoE, Atp5h, Prdx2, Ddah1) were identified (Table 2). Effects of Pon $1^{-/-}$genotype on protein expression were more pronounced and had a greater magnitude (up to 204\%) in mice fed with hyperhomocysteinemic diet, compared with a control diet (up to $27 \%$ ). $\mathrm{HHcy}$ alone changed the expression of one protein $(\mathrm{Ftl})$ that was also affected by the Pon $1^{-/-}$genotype, as well as of four proteins (ApoA-I, Gamt, Prdx2, and Comt) that were not affected by the Pon1-/- genotype alone. Taken together, these findings indicate that a high-Met diet and Pon1 genotype have distinct effects on protein expression and that there is an interaction between the hyperhomocysteinemic diet and Pon $1^{-/-}$genotype that modulates protein expression.

Our previous work has shown that the inactivation of the Pon 1 gene lowers the expression of the antioxidant defense proteins Sod1, Prdx2 and DJ-1 in the brain (Suszyńska-Zajczyk et al., 2014b). In contrast, in the present work we found that in the liver the expression of Sod1, Prdx2 and DJ-1 was not affected by the Pon 1-/genotype. Taken together, these findings suggest that the antioxidant function of Pon1 is organ-specific, i.e. different in the liver and in the brain. While interactions of Pon1 with antioxidant defense proteins can contribute to the antioxidant function in the brain (Suszyńska-Zajczyk et al., 2014), such interactions are not perceptible in the livers of mice fed with a normal chow diet. However, it remains to be determined whether the expression of antioxidant defense proteins is altered in livers of Pon $1^{-/-}$ mice fed with a high-fat diet that exhibit liver steatosis and elevated levels of oxidative stress markers (GarciaHeredia et al., 2013).

Atp5h is a mitochondrial ATP synthase that catalyzes ATP synthesis, utilizing an electrochemical gradient of protons across the inner membrane during oxidative phosphorylation. The ATP synthase system is disturbed under pathophysiological conditions (Das, 2003), including methylmalonic aciduria due to the dysfunction of methylmalonyl CoA mutase, a vitamin $\mathrm{B}_{12}$-dependent enzyme. Toxic metabolites, such as Hcy and methylmalon- 
Table 3. Serum Pon 1 activities in Pon $1^{+/+}$mice are significantly reduced by dietary hyperhomocysteinemia.

\begin{tabular}{|c|c|c|c|c|c|}
\hline \multirow{2}{*}{ Genotype } & \multirow{2}{*}{ Diet } & \multicolumn{2}{|c|}{ POase, $\mathrm{A}_{412} / \mathrm{min}$} & \multicolumn{2}{|c|}{ PhAcase, $\mathrm{A}_{270} / \mathrm{min}$} \\
\hline & & Female $(n=5)$ & Male $(n=4)$ & Female $(n=5)$ & Male $(n=3-7)$ \\
\hline Pon 1+/+ & Std chow & $0.040 \pm 0.008$ & $0.020 \pm 0.004$ & $0.50 \pm 0.05$ & $0.22 \pm 0.02$ \\
\hline Pon $1^{+/+}$ & Std chow $+1 \%$ Met in drinking water, 8 weeks & $0.031 \pm 0.003^{a}$ & $0.012 \pm 0.003^{b}$ & $0.41 \pm 0.02^{c}$ & $0.13 \pm 0.04^{d}$ \\
\hline Pon 1-/- & Std chow & & $0.0005 \pm 0.0001$ & $0.04 \pm 0.02$ & $-0.02 \pm 0.02$ \\
\hline
\end{tabular}

Significantly different from controls: ${ }^{\mathrm{a}} P<0.001, \mathrm{~b} P=0.007, \mathrm{c} P=0.006, \mathrm{~d} P=0.0005$

ic acid, accumulate in tissues and body fluids in aciduria. These metabolites compromise ATP synthase activity, which limits ATP generation and may lead to 'slow onset' excitotoxicity and finally cell death (Das, 2003). Our finding that Atp5h is up-regulated by the Pon1-/- genotype and a high-Met diet suggests that Pon1 interacts with ATP synthase to maintain adequate energy generation in the hyperhomocysteinemic liver.

We found that two methyltransferases, Gamt and Comt, are down-regulated by the Pon $1^{-/-}$genotype in mice fed with a high-Met diet and up-regulated by the diet in Pon $1^{+/+}$animals. Gamt methylates guanidinoacetate using S-adenosylmethionine (AdoMet) in creatine synthesis in the liver and kidney. Creatine is transported through the blood, and taken up by tissues with high energy demands, such as the brain and skeletal muscle. Creatine synthesis is an important determinant of plasma Hcy (Brosnan et al., 2004) and, as the major user of AdoMet methyl groups, accounts for $\sim 75 \%$ of Hcy formation (Mudd et al., 1980). This is reflected by a positive correlation between plasma Hcy and creatine in humans (Rauh et al., 2001). Comt regulates one of the major degradation pathways of catecholamine neurotransmitters by catalyzing the transfer of a methyl group from AdoMet to catecholamines. Comt is also important in the metabolism of catechol drugs used in the treatment of hypertension, asthma, and Parkinson's disease (PD). L-Dopa treatment is associated with the increase in plasma Hcy level in patients with PD (De Bonis et al., 2010). Concomitant treatment with a Comt inhibitor attenuates L-dopa-induced elevation of Hcy level ( $\mathrm{Hu}$ et al., 2013). Our present findings that Gamt and Comt are up-regulated by a high-Met diet and down-regulated by the Pon $1^{-/}$genotype only in animals fed with a high-Met diet, suggest that Pon1 is required for creatine biosynthesis and catechol degradation, respectively, in hyperhomocysteinemic animals.

Of the liver proteins that were not affected by the Pon 1-/- genotype alone, three were up-regulated (Gamt, Prdx2, and Comt) and two (ApoA-I and Atp5h) were down-regulated in mice fed with a hyperhomocysteinemic high-Met diet. Altered expression of one of these proteins has been observed previously in other models of HHcy. For example, Prdx2 is up-regulated in livers of wild type mice fed with $0.5 \%$ Met in drinking water for 2 weeks (DiBello et al., 2010). Hepatic and plasma ApoA-I are significantly reduced in $\mathrm{Cbs}^{-1}$ mice (Jiang et al., 2012), while ApoA-I synthesis is inhibited in severely hyperhomocysteinemic $\mathrm{Cbs}^{-/-} \mathrm{ApoE} \mathrm{E}^{-/-}$mice (Liao et al., 2006). High-density lipoprotein cholesterol is significantly reduced in wild type C57BL/6 mice fed with a $2 \%$-Met in a chow diet for 5 weeks (Velez-Carrasco et al., 2008). Plasma ApoA-I is also significantly reduced in human CBS deficiency (Jiang et al., 2012) and is negatively correlated with plasma Hcy in coronary artery disease patients (Liao et al., 2006).
We identified three proteins, Ddah1, ApoE, and Ftl that were up-regulated by the Pon $1^{-/-}$genotype in mice fed with a control diet. Ddah1 regulates nitric oxide synthesis by removing an inhibitor, asymmetrical dimethylarginine (ADMA), generated by protein degradation (Ogawa et al., 1987). Hcy inhibits Ddah1 activity, causes ADMA accumulation, which in turn inhibits nitric oxide synthase activity, thereby contributing to endothelial dysfunction (Stuhlinger \& Stanger, 2005). Our findings that Ddah1, ApoE, and Ftl were up-regulated by the Pon 1-/genotype suggest that the absence of Pon1 induces protective responses that enhance nitric oxide generation, iron transport, and ApoE synthesis.

Our present finding that a high-Met diet and the Pon1-/- genotype up-regulate the expression of Ftl reveals an additional level of complexity in the ferritin's function. Ferritin is known to participate in one carbon metabolism, which is intimately linked with Hcy metabolism. Specifically, rat ferritin catalyzes folate turnover in vitro and in vivo and may be an important factor in regulating intracellular folate concentrations (Suh et al., 2000) while heavy chain ferritin regulates expression of serine hydroxymethyltransferase by a posttranscriptional mechanism (Oppenheim et al., 2001; Woeller et al., 2007). These processes regulate Hcy levels, and are expected to affect Hcy-thiolactone levels, which in turn would be reflected in the extent of protein $N$-homocysteinylation (Jakubowski et al., 2000; Jakubowski et al., 2008). Furthermore, human and equine ferritins contain substoichiometric amounts of N-linked Hcy (Jakubowski, 2008a). Because HHcy is often caused by folate deficiency, up-regulation of Ftl by high-Met diet might represent a regulatory mechanism that restores folate homeostasis. In this context, our observation that Ftl is also up-regulated by the Pon $1^{-/}$- genotype in mice fed with a control diet (Table 2) suggests that Hcy-thiolactone is involved in Ftl up-regulation.

Although we have not determined how the absence of Pon1 affects the liver protein expression, our findings suggest that Hcy-thiolactone could contribute to specific protein down-regulation in Pon $1^{-/-}$mice fed with a highMet diet. This suggestion is based on our previous findings showing that while HHcy elevates Hcy-thiolactone and other Hcy metabolites, Pon 1-/- genotype elevates only Hcy-thiolactone (Borowczyk et al., 2012a). A possible mechanism of reduced expression of specific proteins in the livers of Pon $1^{-/-}$mice could involve modification by Hcy-thiolactone protein $N$-homocysteinylation followed by increased proteolytic turnover of N-Hcyproteins (Glowacki et al., 2010; Zaabczyk et al., 2011). In this scenario, Gamt, Comt, and Ftl would be targeted for N-homocysteinylation in Pon $1^{-/-}$mice while ApoA-I, At$\mathrm{p} 5 \mathrm{~h}$, and Ddah1 would be targeted in wild type mice fed with high-Met diet. Indeed, in humans Ftl is known to contain N-linked (Jakubowski, 2008a) Hcy while ApoA-I is known to undergo N-homocysteinylation (Jakubowski, 
2002) and plasma N-Hcy-ApoA-I is positively correlated with Hcy levels (Ishimine et al., 2010). Thus, it would be interesting to determine whether $N$-homocysteinylation status of specific liver proteins is altered in Pon $1^{-1-}$ mice.

In conclusion, our findings suggest that Pon1 interacts with diverse cellular pathways that are essential for normal liver homeostasis - from lipoprotein and energy metabolisms, nitric oxide regulation to iron metabolism and antioxidant defenses - and that modulation of these interactions by HHcy underlies the involvement of Hcy in the liver disease. Our findings also suggest that Pon1 has a protective role in the liver, particularly in HHcy.

\section{Acknowledgements}

Supported in part by grants from the American Heart Association (12GRNT9420014), the MNiSW, Poland (N401 065321504, N N302 434439), and the National Science Center, Poland (2011/01/B/NZ1/ 03417, 2011/02/A/NZ1/00010, 2013/09/B/NZ5/02794) 2012/07/B/NZ7/01178,

We thank Diana Shih for kindly providing a breeding pair of Pon1-knockout mice. JS-Z conducted the research, performed the statistical analysis, contributed to the study design and interpretation of the data. HJ designed the research, analyzed the data, wrote the paper, and had primary responsibility for final content. Both authors read and approved the final manuscript.

\section{REFERENCES}

Bayrak A, Bayrak T, Tokgozoglu SL, Volkan-Salanci B, Deniz A, Yavuz B, Alikasifoglu M, Demirpence E (2012) Serum PON-1 activity but not Q192R polymorphism is related to the extent of atherosclerosis. I Atheroscler Thromb 19: 376-384.

Bhattacharyya T, Nicholls SJ, Topol EJ, Zhang RL, Yang X, Schmitt D, Fu XM, Shao MY, Brennan DM, Ellis SG, Brennan ML, Allayee H, Lusis AJ, Hazen SL (2008) Relationship of paraoxonase 1 (PON1) gene polymorphisms and functional activity with systemic oxidative stress and cardiovascular risk. J Am Med Ass 299: 12651276.

Borowczyk K, Shih DM, Jakubowski H (2012a) Metabolism and neurotoxicity of homocysteine thiolactone in mice: evidence for a protective role of paraoxonase 1. I Alzheimer's Dis 30: 225-231.

Borowczyk K, Tisonczyk J, Jakubowski H (2012b) Metabolism and neurotoxicity of homocysteine thiolactone in mice: protective role of bleomycin hydrolase. Amino Acids 43: 1339-1348.

Brosnan JT, Jacobs RL, Stead LM, Brosnan ME (2004) Methylation demand: a key determinant of homocysteine metabolism. Acta Biochim Pol 51: 405-413

Candiano G, Bruschi M, Musante L, Santucci L, Ghiggeri GM, Carnemolla B, Orecchia P, Zardi L, Righetti PG (2004) Blue silver: a very sensitive colloidal Coomassie G-250 staining for proteome analysis. Electrophoresis 25: 1327-1333.

Costa LG, Giordano G, Cole TB, Marsillach J, Furlong CE (2013) Paraoxonase 1 (PON1) as a genetic determinant of susceptibility to organophosphate toxicity. Toxicology 307: 115-122.

Das AM (2003) Regulation of the mitochondrial ATP-synthase in health and disease. Mol Genet Metab 79: 71-82.

De Bonis ML, Tessitore A, Pellecchia MT, Longo K, Salvatore A, Russo A, Ingrosso D, Zappia V, Barone P, Galletti P, Tedeschi G (2010) Impaired transmethylation potential in Parkinson's disease patients treated with L-Dopa. Neurosci Lett 468: 287-291.

DiBello PM, Dayal S, Kaveti S, Zhang D, Kinter M, Lentz SR, Jacobsen DW (2010) The nutrigenetics of hyperhomocysteinemia: quantitative proteomics reveals differences in the methionine cycle enzymes of gene-induced versus diet-induced hyperhomocysteinemia. Mol Cell Proteomics 9: 471-485.

Domagala TB, Lacinski M, Trzeciak WH, Mackness B, Mackness MI, Jakubowski H (2006) The correlation of homocysteine-thiolactonase activity of the paraoxonase (PON1) protein with coronary heart disease status. Cell Mol Biol 52: 4-10.

Farid AS, Honkawa K, Fath EM, Nonaka N, Horii Y (2013) Serum paraoxonase-1 as biomarker for improved diagnosis of fatty liver in dairy cows. BMC Vet Res 9: 73 .
Faurobert M, Pelpoir E, Chaib J (2007) Phenol extraction of proteins for proteomic studies of recalcitrant plant tissues. Methods Mol Biol 355: 9-14.

Ferre N, Camps J, Cabre M, Paul A, Joven J (2001) Hepatic paraoxonase activity alterations and free radical production in rats with experimental cirrhosis. Metabolism 50: 997-1000.

Ferre N, Camps J, Prats E, Vilella E, Paul A, Figuera L, Joven J (2002) Serum paraoxonase activity: a new additional test for the improved evaluation of chronic liver damage. Clin Chem 48: 261-268.

Ferretti G, Bacchetti T, Marotti E, Curatola G (2003) Effect of homocysteinylation on human high-density lipoproteins: a correlation with paraoxonase activity. Metabolism 52: 146-151.

Garcia-Heredia A, Kensicki E, Mohney RP, Rull A, Triguero I, Marsillach J, Tormos C, Mackness B, Mackness M, Shih DM, PedroBotet J, Joven J, Saez G, Camps J (2013) Paraoxonase-1 Deficiency Is Associated with Severe Liver Steatosis in Mice Fed a High-fat High-cholesterol Diet: A Metabolomic Approach. J Proteome Res 12: 1946-1955.

Glowacki R, Bald E, Jakubowski H (2010) Identification and origin of Nepsilon-homocysteinyl-lysine isopeptide in humans and mice. Amino Acids 39: 1563-1569.

Glowacki R, Jakubowski H (2004) Cross-talk between Cys34 and lysine residues in human serum albumin revealed by N-homocysteinylation. J Biol Chem 279: 10864-10871.

Hirsch S, Poniachick J, Avendano M, Csendes A, Burdiles P, Smok G, Diaz JC, de la Maza MP (2005) Serum folate and homocysteine levels in obese females with non-alcoholic fatty liver. Nutrition 21: $137-141$.

Hu XW, Qin SM, Li D, Hu LF, Liu CF (2013) Elevated homocysteine levels in levodopa-treated idiopathic Parkinson's disease: a metaanalysis. Acta Neurol Scand 128: 73-82.

Ishimine N, Usami Y, Nogi S, Sumida T, Kurihara Y, Matsuda K, Nakamura K, Yamauchi K, Okumura N, Tozuka M (2010) Identification of N-homocysteinylated apolipoprotein AI in normal human serum. Ann Clin Biochem 47: 453-459.

Jakubowski H (1999) Protein homocysteinylation: possible mechanism underlying pathological consequences of elevated homocysteine levels. FASEB J 13: 2277-2283.

Jakubowski H (2000) Calcium-dependent human serum homocysteine thiolactone hydrolase. A protective mechanism against protein Nhomocysteinylation. J Biol Chem 275: 3957-3962.

Jakubowski H (2002) Homocysteine is a protein amino acid in humans. Implications for homocysteine-linked disease. J Biol Chem 277: 30425-30428

Jakubowski H (2008a) New method for the determination of protein N-linked homocysteine. Anal Biochem 380: 257-261.

Jakubowski H (2008b). Paraoxonase 1 (PON1), a junction between the metabolisms of homocysteine and lipids. Proteins Cell Regul 6: $87-102$.

Jakubowski H, Boers GH, Strauss KA (2008) Mutations in cystathionine $\{$ beta\}-synthase or methylenetetrahydrofolate reductase gene increase N-homocysteinylated protein levels in humans. FASEB J 22: 4071-4076

Jakubowski H, Perla-Kajan J, Finnell RH, Cabrera RM, Wang H, Gupta S, Kruger WD, Kraus JP, Shih DM (2009) Genetic or nutritional disorders in homocysteine or folate metabolism increase protein $\mathrm{N}$ homocysteinylation in mice. FASEB J 23: 1721-1727.

Jakubowski H, Zhang L, Bardeguez A, Aviv A (2000) Homocysteine thiolactone and protein homocysteinylation in human endothelial cells: implications for atherosclerosis. Circ Res 87: 45-51.

Jiang H, Stabler SP, Allen RH, Maclean KN (2012) Altered expression of apoA-I, apoA-IV and PON-1 activity in CBS deficient homocystinuria in the presence and absence of treatment: possible implications for cardiovascular outcomes. Mol Genet Metab 107: 55-65.

Kaplowitz N, Than TA, Shinohara M, Ji C (2007) Endoplasmic reticulum stress and liver injury. Semin Liver Dis 27: 367-377.

Lacinski M, Skorupski W, Cieslinski A, Sokolowska J, Trzeciak WH, Jakubowski H (2004) Determinants of homocysteine-thiolactonase activity of the paraoxonase-1 (PON1) protein in humans. Cell Mol Biol 50: 885-893.

Liao D, Tan H, Hui R, Li Z, Jiang X, Gaubatz J, Yang F, Durante W, Chan L, Schafer AI, Pownall HJ, Yang X, Wang H (2006) Hyperhomocysteinemia decreases circulating high-density lipoprotein by inhibiting apolipoprotein A-I Protein synthesis and enhancing HDL cholesterol clearance. Circ Res 99: 598-606.

Luczak M, Formanowicz D, Pawliczak E, Wanic-Kossowska M, Wykretowicz A, Figlerowicz M (2011) Chronic kidney disease-related atherosclerosis - proteomic studies of blood plasma. Proteome Sci 9: 25 .

Mackness B, Beltran-Debon R, Aragones G, Joven J, Camps J, Mackness M (2010) Human tissue distribution of paraoxonases 1 and 2 mRNA. IUBMB Life 62: 480-482.

Marsillach J, Ferre N, Vila MC, Lligona A, Mackness B, Mackness M, Deulofeu R, Sola R, Pares A, Pedro-Botet J, Joven J, Caballeria J, Camps J (2007) Serum paraoxonase-1 in chronic alcoholics: relationship with liver disease. Clin Biochem 40: 645-650. 
Marsillach J, Mackness B, Mackness M, Riu F, Beltran R, Joven J, Camps J (2008) Immunohistochemical analysis of paraoxonases-1, 2 , and 3 expression in normal mouse tissues. Free Radic Biol Med 45: $146-157$.

Mudd SH, Ebert MH, Scriver CR (1980) Labile methyl group balances in the human: the role of sarcosine. Metabolism 29: 707-720.

Ogawa T, Kimoto M, Sasaoka K (1987) Occurrence of a new enzyme catalyzing the direct conversion of NG,NG-dimethyl-L-arginine to L-citrulline in rats. Biochem Biophys Res Commun 148: 671-677.

Oppenheim EW, Adelman C, Liu X, Stover PJ (2001) Heavy chain ferritin enhances serine hydroxymethyltransferase expression and de novo thymidine biosynthesis. J Biol Chem 276: 19855-19861.

Perla-Kajan J, Jakubowski H (2010) Paraoxonase 1 protects against protein N-homocysteinylation in humans. FASEB J 24: 931-936.

Perla-Kajan J, Jakubowski H (2012) Paraoxonase 1 and homocysteine metabolism. Amino Acids 43: 1405-1417.

Perla-Kajan J, Stanger O, Luczak M, Ziolkowska A, Malendowicz LK, Twardowski T, Lhotak S, Austin RC, Jakubowski H (2008) Immunohistochemical detection of N-homocysteinylated proteins in humans and mice. Biomed Pharmacother 62: 473-479.

Rauh M, Verwied S, Knerr I, Dorr HG, Sonnichsen A, Koletzko B (2001) Homocysteine concentrations in a German cohort of 500 individuals: reference ranges and determinants of plasma levels in healthy children and their parents. Amino Acids 20: 409-418.

Robert K, Chasse JF, Santiard-Baron D, Vayssettes C, Chabli A, Aupetit J, Maeda N, Kamoun P, London J, Janel N (2003) Altered gene expression in liver from a murine model of hyperhomocysteinemia. I Biol Chem 278: 31504-31511.

Shevchenko A, Shevchenko A (2001) Evaluation of the efficiency of in-gel digestion of proteins by peptide isotopic labeling and MALDI mass spectrometry. Anal Biochem 296: 279-283.

Shih DM, Gu L, Xia YR, Navab M, Li WF, Hama S, Castellani LW, Furlong CE, Costa LG, Fogelman AM, Lusis AJ (1998) Mice lacking serum paraoxonase are susceptible to organophosphate toxicity and atherosclerosis. Nature 394: 284-287.

Stuhlinger MC, Stanger O (2005) Asymmetric dimethyl-L-arginine (ADMA): a possible link between homocyst(e)ine and endothelial dysfunction. Curr Drug Metab 6: 3-14.

Suh JR, Oppenheim EW, Girgis S, Stover PJ (2000) Purification and properties of a folate-catabolizing enzyme. I Biol Chem 275: 3564635655 .
Suszynska-Zajczyk J, Wroblewski J, Utyro O, Luczak M, Marczak L, Jakubowski H (2014a) Bleomycin hydrolase and hyperhomocysteinemia modulate the expression of mouse proteins involved in liver homeostasis. Amino Acids 46: 1471-1480.

Suszyńska-Zajczyk J, Łuczak M, Marczak L, Jakubowski H (2014b) Inactivation of the paraoxonase 1 gene affects the expression of mouse brain proteins involved in neurodegeneration. I Alzheimers Dis 42: 247-260.

Undas A, Jankowski M, Twardowska M, Padjas A, Jakubowski H, Szczeklik A (2005) Antibodies to N-homocysteinylated albumin as a marker for early-onset coronary artery disease in men. Thromb Haemost 93: 346-350.

Undas A, Perla J, Lacinski M, Trzeciak W, Kazmierski R, Jakubowski $\mathrm{H}$ (2004) Autoantibodies against N-homocysteinylated proteins in humans: implications for atherosclerosis. Stroke 35: 1299-1304.

Velez-Carrasco W, Merkel M, Twiss CO, Smith JD (2008) Dietary methionine effects on plasma homocysteine and HDL metabolism in mice. J Nutr Biochem 19: 362-370.

Wehr H, Bednarska-Makaruk M, Graban A, Lipczynska-Lojkowska W, Rodo M, Bochynska A, Ryglewicz D (2009) Paraoxonase activity and dementia. I Neurol S ci 283: 107-108.

Werstuck GH, Lentz SR, Dayal S, Hossain GS, Sood SK, Shi YY, Zhou J, Maeda N, Krisans SK, Malinow MR, Austin RC (2001) Homocysteine-induced endoplasmic reticulum stress causes dysregulation of the cholesterol and triglyceride biosynthetic pathways. $J$ Clin Invest 107: 1263-1273.

Woeller CF, Fox JT, Perry C, Stover PJ (2007) A ferritin-responsive internal ribosome entry site regulates folate metabolism. J Biol Chem 282: 29927-29935.

Zaabczyk M, Glowacki R, Machnik A, Herod P, Kazek G, Jakubowski H, Undas A (2011) Elevated concentrations of Nvarepsilon-homocysteinyl-lysine isopeptide in acute myocardial infarction: links with ADMA formation. Clin Chem Lab Med 49: 729-735.

Zhang C, Peng W, Jiang X, Chen B, Zhu J, Zang Y, Zhang J, Zhu T, Qin J (2008) Transgene expression of human PON1 Q in mice protected the liver against CCl4-induced injury. J Gene Med 10: 94-100.

Zhou J, Moller J, Danielsen CC, Bentzon J, Ravn HB, Austin RC, Falk E (2001) Dietary supplementation with methionine and homocysteine promotes early atherosclerosis but not plaque rupture in ApoE-deficient mice. Arterioscler Thromb Vasc Biol 21: 1470-1476. 